
КРОВОИЗЛИЯНИЯ В УСЛОВИЯХ ЭКСТРЕННОГО ПРИЕМНОГО ПОКОЯ

\author{
${ }^{1}$ Научно-исследовательский институт - Краевая клиническая больница № 1 им. проф. С.В. Очаповского, Краснодар, Россия \\ ${ }^{2}$ Кубанский государственный медицинский университет, Краснодар, Россия \\ Е.И. Зяблова, НИИ - ККБ № 1 им. проф. С.В. Очаповского, 350086, Краснодар, ул. Российская, 140, \\ elenazyablova@inbox.ru
}

Поступила в редакцию 5 ноября 2020 г. Исправлена 12 января 2021 г. Принята к печати 10 февраля 2020 г.

Актуальность

Внутричерепное кровоизлияние является наиболее серьезным проявлением разрыва церебральной аневризмы, а субарахноидальное кровоизлияние (САК) - самой частой клинико-анатомической формой. Лечебная тактика при нетравматическом САК (нСАК) варьирует от консервативного до неотложного хирургического лечения и зависит от источника кровоизлияния. В настоящее время поиск источников проводится с помощью различных методов лучевой диагностики.

Цель Сравнить изображения интракраниальных артерий, полученные при компьютерно-томографической ангиографии (КТ-АГ), с данными церебральной ангиографии в остром периоде нетравматического кровоизлияния в субарахноидальное пространство.

Материал и методы Ретроспективный анализ историй болезни 242 пациентов с острыми нСАК за период с сентября 2017 г. по сентябрь 2019 г., обследованных в условиях экстренного приемного покоя НИИ - Краевой клинической больницы № 1 им. проф. С.В. Очаповского.

Результаты По данным КТ-АГ источник кровоизлияния верифицирован у 212 пациентов (87\%), из них в 84,0\% случаев (205 пациентов) причиной нСАК явились разорвавшиеся церебральные аневризмы. У 3 пациентов выявлены разрывы артериовенозных мальформаций $(1,2 \%)$. У 4 больных диагноз «Церебральные аневризмы» исключен в связи с установлением гипертензивного характера внутричерепного кровоизлияния (1,7\%). У 30 пациентов при КТ-АГ сосудистой патологии не выявлено. По результатам только КТ-АГ микрохирургически прооперировано 225 пациентов (93\%), с использованием внутрисосудистого доступа - 12 пациентов (5\%). Среди 30 больных, у которых сосудистой патологии на КТ-АГ выявлено не было, у 6 по данным церебральной ангиографии обнаружены одиночные аневризмы: внутренней сонной артерии- у 3 больных, средней мозговой артерии - у 2 , перикаллезной артерии - у 1 пациента.

Выводы КТ-АГ - ключевой метод неинвазивной диагностики источника нСАК в условиях экстренного приемного покоя. Выявление сосудистой патологии интракраниальных артерий при КТ-АГ позволяет в $87 \%$ случаев воздержаться от проведения инвазивных методов исследований. Отсутствие сосудистой патологии на КТ-АГ при наличии массивного базального САК, выявление при КТ-АГ множественных и «сложных» аневризм, а также церебральных артериовенозных мальформаций головного мозга остаются показаниями к проведению церебральной ангиографии.

Ключевые слова: КТ-ангиография, аневризма, субарахноидальное кровоизлияние

Цитировать: Зяблова Е.И., Ткачев В.В., Порханов В.А. Вклад КТ-ангиографии в верификацию источника нетравматического внутричерепного кровоизлияния в условиях экстренного приемного покоя. Инновационная медицина Кубани. 2021;(1):34-38. https://doi.org/10.35401/2500-0268-2021-21-1-34-38

() Elena I. Zyablova 1", Vyacheslav V. Tkachev ', Vladimir A. Porhanov 1,2

\title{
CT ANGIOGRAPHY FOR DETECTING THE CAUSE OF INTRACRANIAL HEMORRHAGE IN THE EMERGENCY DEPARTMENT
}

\footnotetext{
${ }^{1}$ Research Institute - Ochapovsky Regional Hospital no. 1, Krasnodar, Russian Federation

${ }^{2}$ Kuban State Medical University, Krasnodar, Russian Federation

$\triangle$ * Elena I. Zyablova, Research Institute - Ochapovsky Regional Hospital no. 1, ul. Rossiyskaya, 140, Krasnodar, 350086, elenazyablova@inbox.ru

Received: 5 November 2020. Received in revised form: 12 January 2021. Accepted: 10 February 2021.
}

Background

Intracranial hemorrhage is the most serious manifestation of a ruptured cerebral aneurysm, and subarachnoid hemorrhage (SAH) is the most common clinical and anatomical form. The treatment strategy for SAH varies from conservative to emergency surgical treatment and depends on the source of the hemorrhage. Currently, the search for sources is carried out using various methods of diagnostic radiology.

Objective To compare the images of intracranial arteries obtained by computed tomography (CT) angiography with the data of cerebral angiography in the acute period of hemorrhage in the subarachnoid space. 
Material and Methods

Results

Conclusion

Keywords:

Cite this article as:
We retrospectively analyzed the medical records of 242 patients with acute SAHs from September 2017 to September 2019, examined in the emergency room of the Research Institute - Ochapovsky Regional Hospital no. 1.

According to CT angiography, the initially occult vascular lesion was verified in 212 patients (87\%), of which in $84.0 \%$ of cases (205 patients) the cause of SAH was ruptured cerebral aneurysms. In 3 patients, ruptures of arteriovenous malformations were detected (1.2\%). In 4 patients, the "cerebral aneurysms" diagnosis was excluded due to the establishment of a hypertensive nature of intracranial hemorrhage (1.7\%). In 30 patients, CT angiography revealed no vascular pathology. According to the results of CT angiography only, 225 patients $(93 \%)$ were microsurgically operated on, and 12 patients $(5 \%)$ were operated on using intravascular access. Among 30 patients whose vascular pathology was not detected by CT angiography, 6 patients were found to have single aneurysms according to cerebral angiography: the internal carotid artery - in 3 patients, the middle cerebral artery - in 2, and the pericallous artery - in 1 patient.

CT angiography is a key tool of non-invasive diagnosis of the source of SAH in emergency departments. The absence of vascular pathology on CT angiography in the presence of massive basal SAH, the detection of multiple and "complex" aneurysms, as well as cerebral arteriovenous malformations of the brain during CT angiography remain indications for cerebral angiography.

CT angiography, aneurysm, subarachnoid hemorrhage

Zyablova E.I., Tkachev V.V., Porhanov V.A. CT angiography for detecting the cause of intracranial hemorrhage in the emergency department. Innovative Medicine of Kuban. 2021;(1):34-38. https://doi. org/10.35401/2500-0268-2021-21-1-34-38

\section{АКТУАЛЬНОСТЬ}

Наиболее серьезным проявлением и частой клинико-анатомической формой кровоизлияния из церебральной аневризмы (ЦА) является субарахноидальное кровоизлияние (САК) $[1,2]$.

По данным Всемирной организации здравоохранения, заболеваемость САК значительно варьирует по всему миру - от 2,0 до 22,5 на 100 тыс. чел. [3]. Несмотря на улучшения в диагностических и терапевтических методах, уровень смертности от острого нетравматического САК (нСАК) значимо не изменился: по данным различных авторов, он колеблется от 30 до $50 \%$, более $15 \%$ пациентов умирают, не обратившись за медицинской помощью. Выжившие позднее часто страдают от хронических головных болей, нарушений сна, нейрокогнитивных и психиатрических проблем, которые отрицательно сказываются на качестве жизни $[2,3]$.

Установлено, что в $85 \%$ случаев причиной всех нСАК являются разрывы аневризм [4]. Среди более редких причин нСАК следует назвать разрывы артериовенозных мальформаций, артериальную гипертонию, патологические состояния, обусловленные нарушением свертываемости крови, васкулопатии и пр. $[5,6]$. Пол и возраст пациентов с данной патологией могут значимо различаться, наиболее часто это женщины среднего возраста - до 60 лет [7].

Лечебная тактика при нСАК различной этиологии существенно варьирует от консервативного лечения до неотложного вмешательства по жизненным показаниям, причем выявление источника САК играет в ней ключевую роль. В настоящее время непосредственная верификация источника возможна при помощи: спиральной компьютерно-томографической ангиографии (КТ-АГ), магнитно-резонансной ангиографии (МР-АГ) и цифровой субтракционной церебральной ангиографии (ЦАГ) [8].
Несмотря на широкую доступность оборудования для нейровизуализации, несвоевременная и ошибочная диагностика источника внутричерепного кровоизлияния остается распространенным явлением [9].

\section{ЦЕЛЬ}

Проведение сравнительного анализа изображений, полученных при КТ-АГ сосудов головного мозга, с данными ЦАГ в остром периоде нетравматического кровоизлияния в субарахноидальное пространство.

\section{МАТЕРИАЛ И МЕТОДЫ}

Проведен ретроспективный анализ историй болезни 242 пациентов с острыми нСАК за период с сентября 2017 г. по сентябрь 2019 г. Все больные обследованы в условиях экстренного приемного покоя НИИ Краевой клинической больницы № 1 им. проф. С.В. Очаповского.

Лучевые исследования проводились на компьютерном томографе Definition Flash (Siemens). Укладка пациента была стандартной, предварительно выполнялись две топограммы для разметки областей исследования (области шеи и головы), затем осуществлялось сканирование головного мозга в нативном виде и режиме ангиографии.

Нативное сканирование головы проводилось от уровня основания черепа до уровня его мягких тканей, КТ-АГ брахиоцефальных артерий - от уровня дуги аорты до уровня дистальных отделов интракраниальных артерий. Контрастный препарат («Омнипак», GE Healthcare, США, концентрация 350 мг/мл) вводился в локтевую вену со скоростью 4-5 мл/сек с помощью шприца-инжектора. Объем контрастного препарата составлял 50-80 мл.

Реконструкции брахиоцефальных артерий осуществлялись с толщиной среза 0,75 мм, на рабочей 
Таблица 1

Выраженность субарахноидального кровоизлияния по шкале Fisher

Table 1

Severity of subarachnoid hemorrhage on the Fisher scale

\begin{tabular}{|c|c|c|}
\hline $\begin{array}{l}\text { Сте- } \\
\text { пень }\end{array}$ & Описание & $\begin{array}{c}\text { Компьютерно- } \\
\text { томографическое } \\
\text { изображение }\end{array}$ \\
\hline I & $\begin{array}{l}\text { Нет субарахноидально- } \\
\text { го кровоизлияния, } \\
\text { нет внутрижелудочко- } \\
\text { вых гематом }\end{array}$ & \\
\hline II & $\begin{array}{l}\text { Диффузное } \\
\text { субарахноидальное } \\
\text { кровоизлияние, } \\
\text { менее } 1 \text { мм }\end{array}$ & \\
\hline III & $\begin{array}{l}\text { Локальные сгустки } \\
\text { крови толщиной } \\
\text { более } 1 \text { мм }\end{array}$ & \\
\hline IV & $\begin{array}{l}\text { Внутримозговое и/или } \\
\text { внутрижелудочковое } \\
\text { кровоизлияние при } \\
\text { наличии или отсутствии } \\
\text { субарахноидального } \\
\text { кровоизлияния }\end{array}$ & \\
\hline
\end{tabular}

станции VIA в приложении 3D и Vascular (Siemens, Германия) проводился анализ брахиоцефальных сосудов (анатомия, наличие аневризм).

При нативной КТ прежде всего устанавливался факт нетравматического кровоизлияния, оценивались состояние паренхимы головного мозга, величина смещения срединных структур головного мозга, при наличии внутримозгового и внутрижелудочкового кровоизлияния - их характеристики, а также состояние субдурального, конвекситального субарахноидального пространств и базальных цистерн. Выраженность САК классифицировали по шкале Fisher (the Modified Fisher Grading Scale) (табл. 1), внутрижелудочкового кровоизлияния (ВЖК) - по шкале Graeb (the Modified Graeb Score) (табл. 2).

Кроме поиска источника кровотечения, оценивались различные варианты развития Виллизиева круга, проводился анализ сосудов шеи на предмет атеросклеротического поражения, аномалий и вариантов развития для выбора последующего проведе- ния эндоваскулярного или открытого хирургического лечения.

При КТ-АГ осуществлялся поиск возможного источника внутричерепного кровоизлияния. При наличии аневризмы определялись: размер, число, форма и локализация патологии, индивидуальные анатомические особенности аневризмы и несущей ее артерии, детали их взаимоотношений с костными структурами основания черепа.

Церебральная ангиография проводилась на аппаратаx: General Electric Innova 3000, Siemens Axiom Artis dTC. Выполнялось нативное и субтракционное исследование экстра- и интракраниальных отделов всех брахиоцефальных артерий. При выявлении патологии дополнительно проводилось ротационное исследование пораженного сосудистого бассейна. По данным ангиографии определяли расположение, размеры и анатомические особенности имеющихся у пациента аневризм и несущих артерий, а также выраженность и распространенность церебрального артериоспазма.

\section{РЕЗУЛЬТАТЫ}

По выраженности САК согласно шкале Фишера у 13,1\% пациентов (18 чел.) наблюдалась II степень САК, у 50,4\% (69) - III и у 36,5\% (50) - IV степень. Пациентов с I степенью выявлено не было.

По тяжести внутрижелудочковых кровоизлияний пациенты распределялись следующим образом: легкие ВЖК - 54\% (27 случаев), среднетяжелые - 30\% (15), тяжелые - $16 \%$ (8).

По данным КТ-АГ источник кровоизлияния верифицирован у 212 пациентов (87\%), из них в $84,0 \%$ случаев (205 пациентов) причиной нСАК являлись разорвавшиеся ЦА. У 3 пациентов выявлены разрывы артериовенозных мальформаций $(1,2 \%)$. У 4 пациентов диагноз ЦА исключен в связи с установлением гипертензивного характера внутричерепного кровоизлияния $(1,7 \%)$. У 30 пациентов при КТ-АГ сосудистой патологии выявлено не было.

Общее количество аневризм, выявленных по данным КТ-АГ у 205 пациентов, составило 244. Чаще встречались одна - 83,9\% (172 пациентов) и две аневризмы - 13,6\% (28 пациентов), в меньшем количестве случаев - 3 аневризмы (1\%, 2 пациента), 4 аневризмы (1\%, 2 пациента) и 5 аневризм $(0,5 \%, 1$ пациент). В большинстве случаев обнаруживались мешотчатые аневризмы - 98,8\% (241 случай). В большей части аневризмы локализовались на уровне средней мозговой артерии - 37,3\% (91 случай) и передней мозговой артерии - $11,9 \%$ (29 случаев), в меньшей на базилярной артерии $-0,4 \%$ (1 случай) и задней нижней мозжечковой артерии - $0,4 \%$ (1 случай). Размеры аневризм составляли менее 4 мм в $21,3 \%$ (52 случая), 4-8 мм - в 47,6\% (116 случаев), 8-12 мм - в 27,9\% (68 случаев), более 12 мм - 3,2\% (8 случаев). 
Таблица 2

Тяжесть внутрижелудочковых кровоизлияний (ВЖК) по шкале Graeb

Table 2

Severity of intraventricular hemorrhages on the Graeb scale

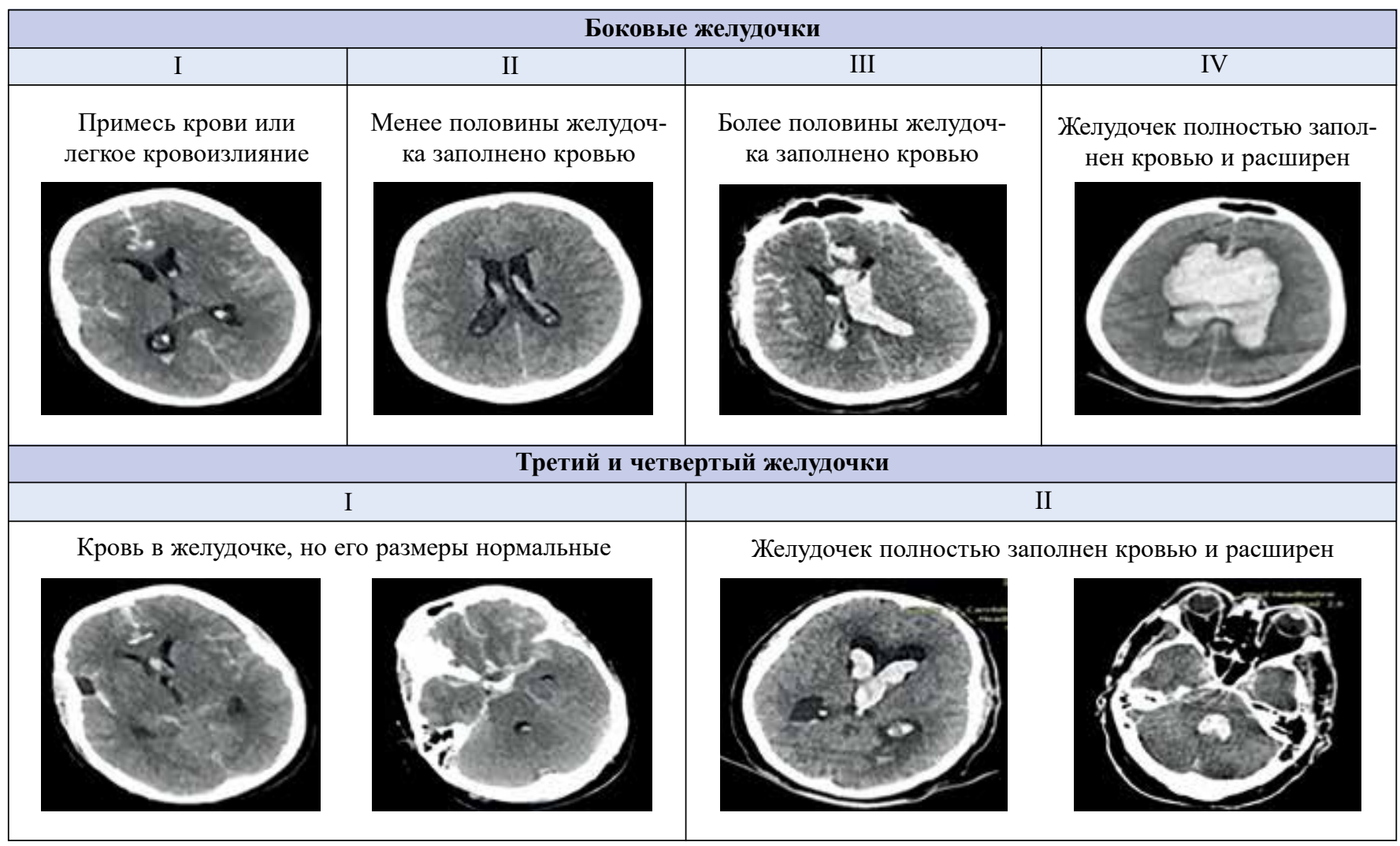

1-4 балла - легкие ВЖК

5-8 баллов - среднетяжелые ВЖК

9-12 баллов - тяжелые ВЖК
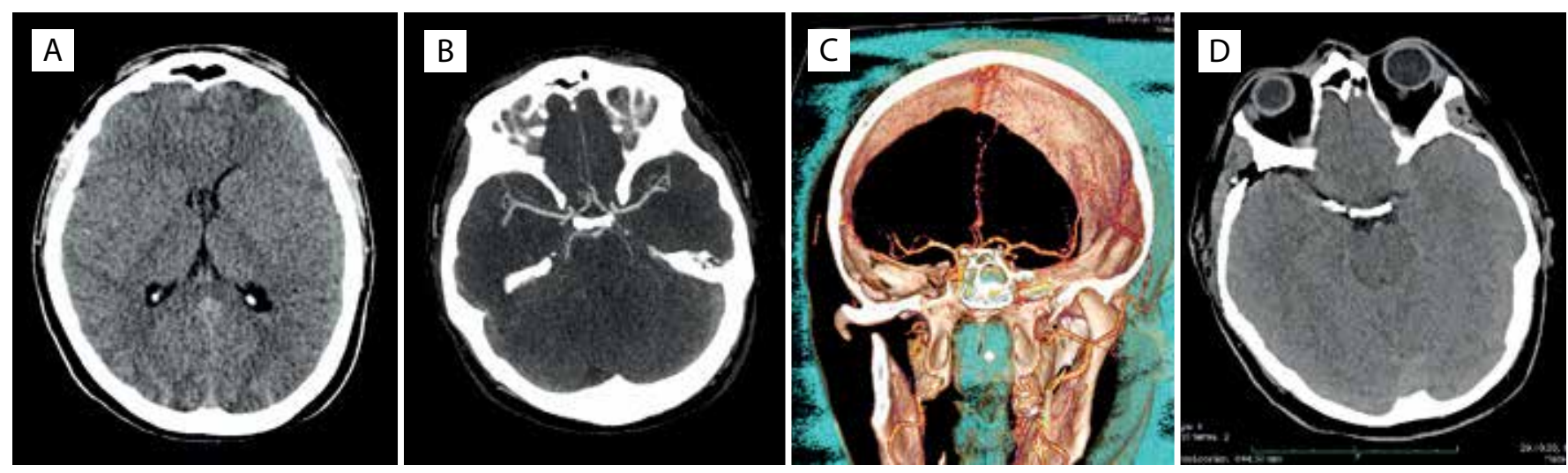

Рисунок 1. Клинический пример. Мужчина, 31 год. Заболел остро. По месту жительства выполнена люмбальная пункиия (эритроциты в большом количестве). Эвакуирован по линии санавиации в НИИ - ККБ № 1

A - На нативной компьютерной томографии - субарахноидально-вентрикулярное кровоизлияние, Fisher IV, Graeb II.

В, C - При компьютерно-томографической ангиографии - аневризма устья правой задней соединительной артерии, подтвержденная на церебральной ангиографии.

$\mathrm{D}$ - Состояние после костно-пластической краниотомии справа, клипирование разорвавшейся аневризмы устья правой задней соединительной артерии

Figure 1. Clinical case of the 31-year-old male patient. He became acutely ill. At the place of residence, a lumbar puncture was performed (red blood cells were in large numbers). He was evacuated via the air medical service to the Research Institute - Ochapovsky Regional Hospital no. 1

A - Non-contrast computed tomography showed subarachnoid-ventricular hemorrhage, Fisher IV, Graeb II.

$\mathrm{B}, \mathrm{C}-\mathrm{Computed}$ tomography angiogram demonstrated aneurysm of the mouth of the right posterior communicating artery, confirmed by cerebral angiography.

$\mathrm{D}$ - Condition after bone-plastic craniotomy on the right, clipping of a ruptured aneurysm of the mouth of the right posterior communicating artery 
Среди 30 пациентов, у которых сосудистой патологии на КТ-АГ выявлено не было, у 6 по данным ЦАГ обнаружились одиночные аневризмы: внутренней сонной артерии - у 3 больных, средней мозговой артерии - у 2 и перикаллезной артерии - у 1 пациента. В двух случаях диаметр ЦА превышал 3 мм, а у 4 был менее 3 мм. Одна из шести не выявленных при КТ-АГ аневризм располагалась вне зоны сканирования на левой перикаллезной артерии. Оставшиеся аневризмы локализовались на уровне внутренней сонной артерии (2 случая), средней мозговой артерии (2 случая), внутренней сонной артерии - задней соединительной артерии (1 случай).

Ретроспективный анализ КТ-АГ опытным рентгенологом показал, что среди пропущенных на КТ аневризм: 1 связана с нарушением протокола сканирования, 1 - с неопытностью рентгенолога, оценивавшего исследование (менее 3 лет стажа), 4 - с малыми размерами аневризмы (менее 3 мм).

По результатам только КТ-АГ микрохирургически прооперировано 225 пациентов (93\%) (рис. 1), с использованием внутрисосудистого доступа - 12 пациентов $(5 \%)$.

После выполнения лучевой диагностики 5 пациентов не оперированы в связи с тяжестью состояния (2\%).

\section{ВЫВОДЫ}

КТ-АГ является ключевым методом неинвазивной диагностики источника нСАК в условиях экстренного приемного покоя. Исследование должно проводиться по строгому регламенту и оцениваться опытным рентгенологом.

Наши данные подтверждают, что аневризмы интракраниальных артерий являются наиболее частой причиной нетравматических САК. Выявление сосудистой патологии интракраниальных артерий при КТ-АГ позволяет в $87 \%$ случаев воздержаться от проведения инвазивных методов исследований.

Отсутствие сосудистой патологии на КТ-АГ при наличии массивного базального САК, выявление при КТ-АГ множественных и «сложных» аневризм, а также церебральных артериовенозных мальформаций головного мозга остаются показаниями к проведению дигитальной субтракционной церебральной ангиографии.

\section{ЛИТЕРАТУPA/REFERENCES}

1. Коновалов А.Н., Крылов В.В., Филатов Ю.М. и др. Рекомендательный протокол ведения больных с субарахноидальным кровоизлиянием вследствие разрыва аневризм головного мозга. Журнал «Вопросы нейрохирургии» им. Н.Н. Бурденко. 2006;3:3-10.

Konovalov AN, Krylov VV, Filatov YuM, et al. Advisable management protocol for patients with subarachnoidal hemorrhage resulting from cerebral vascular aneurysmal rupture. Burdenko's Journal of Neurosurgery. 2006;3:3-10. (In Russ.).

2. Hacein-Bey L, Provenzale JM. Current imaging assessment and treatment of intracranial aneurysms. AJR Am J
Roentgenol. 2011;196(1):32-44. PMID: 21178044. https://doi. org/10.2214/AJR.10.5329

3. Howard BM, $\mathrm{Hu}$ R, Barrow JW, Barrow DL. Comprehensive review of imaging of intracranial aneurysms and angiographically negative subarachnoid hemorrhage. Neurosurg Focus. 2019;47(6):E20. PMID: 31786554. https://doi. org/10.3171/2019.9.FOCUS19653

4. Oppenheim C, Domigo V, Gauvrit JY, et al. Subarachnoid hemorrhage as the initial presentation of dural sinus thrombosis. AJNR Am J Neuroradiol. 2005;26(3):614-617. PMID: 15760875.

5. Marder CP, Narla V, Fink JR, Tozer Fink KR. Subarachnoid hemorrhage: beyond aneurysms. AJR Am J Roentgenol. 2014;202(1):25-37. PMID: 24370126. https://doi. org/10.2214/AJR.12.9749

6. Berlit P. Diagnosis and treatment of cerebral vasculitis. Ther Adv Neurol Disord. 2010;3(1):29-42. PMID: 21180634. PMCID: PMC3002614. https://doi.org/10.1177/1756285609347123

7. van Gijn J, Rinkel GJ. Subarachnoid haemorrhage: diagnosis, causes and management. Brain. 2001;124:249-278. PMID: 11157554. https://doi.org/10.1093/brain/124.2.249

8. Корниенко В.Н., Пронин И.Н. Диагностическая нейрорадиология. 2008. Т. 1.

Korniyenko VN, Pronin IN. Diagnostic Neuroradiology. 2008. Vol. 1. (In Russ.).

9. Marcolini E, Hine J. Approach to the diagnosis and management of subarachnoid hemorrhage. West J Emerg Med. 2019;20(2):203-211. PMID: 30881537. PMCID: PMC6404699. https://doi.org/10.5811/westjem.2019.1.37352

\section{СВЕДЕНИЯ ОБ АВТОРАХ}

Зяблова Елена Игоревна, к. м. н., заведующая рентгеновским отделением, НИИ - ККБ № 1 им. проф. С.В. Очаповского (Краснодар, Россия). https://orcid.org/0000-0002-6845-5613

Ткачев Вячеслав Валерьевич, д. м. н., заведующий нейрохирургическим отделением № 2, НИИ - ККБ № 1 им. проф. С.В. Очаповского (Краснодар, Россия). https://orcid.org/00000002-3168-958X

Порханов Владимир Алексеевич, академик РАН, д. м. Н., профессор, главный врач НИИ - ККБ № 1 им. проф. С.В. Очаповского; заведующий кафедрой онкологии с курсом торакальной хирургии, факультет повышения квалификации и профессиональной переподготовки специалистов, Кубанский государственный медицинский университет (Краснодар, Россия). https://orcid.org/0000-0003-0572-1395

Финансирование Исследование не имело спонсорской поддержки. Конфликт интересов Авторы заявляют об отсутствии конфликта интересов.

\section{AUTHOR CREDENTIALS}

Elena I. Zyablova, Cand. of Sci. (Med.), Head of the Radiology Department, Research Institute - Ochapovsky Regional Hospital no. 1 (Krasnodar, Russian Federation). https://orcid. org/0000-0002-6845-5613

Vyacheslav V. Tkachev, Dr. of Sci. (Med.), Head of the Neurosurgery Department no. 2, Research Institute - Ochapovsky Regional Hospital no. 1 (Krasnodar, Russian Federation). https:// orcid.org/0000-0002-3168-958X

Vladimir A. Porhanov, Member of the Russian Academy of Sciences, Dr. of Sci. (Med.), Professor, Chief Doctor of the Research Institute - Ochapovsky Regional Hospital no. 1; Head of the Department of Oncology with the Course of Thoracic Surgery, Department of Proficiency Enhancement, Kuban State Medical University (Krasnodar, Russian Federation). https://orcid. org/0000-0003-0572-1395

Funding: the study was not sponsored. Conflict of interest: none declared. 